In foggy or stormy weather, the vessel is kept under command, if possible, to clear any icebergs seen, but if not able to move, should be placed broadside to the wind or before it ; the danger of being head to wind is, that if the ice anchors carry away and a crack forms under the stern, the force of concussion with the ice may damage the rudder fittings irreparably.

When crossing the water at night and approaching ice, the vessel is always stopped to take the shock gently, and because icebergs loom much like field ice. The whereabouts of water is inevitably shown by a dark horizon, and that of ice by the blink or " glinny."

There are no laws regulating the prosecution of the seal fishery except one passed in 1873, forbidding the departure of sailing vessels before the 5 th, and steamers before the Ioth of March.

Little Placentia, Newfoundland, June 22

\section{THE INTERNATIONAL GEOGRAPHICAL CONGRESS}

THE Organising Committee of the Geographical Congress to be held in Paris in the spring of 1875 have josned a programme of subjects to be discussed during the meeting. The "Commissaire Général" of the Congress is M. le Baron Reille, to whom, at Io, Boulevard Latour-Maubourg, all communications ought to be addressed. The Congress will last eight days, the first of which will be devoted to a general meeting for the purpose of inaugurating the work of the Congress. The members will be divided into sections, each of which will meet separately on the following forenoons to discuss the subjects connected with the section; the afternoons will be devoted to general séances. Duxing the meeting of the Congress there will be an exhibition of objects relating to the study of geography, and on the last day prizes will be awarded to exhibitors. The transactions of the Congress will be ultimately published. The conditions of subscription are much the same as those of the French Association for the Advancement of Science.

The sectional sub-committees have provisionally prepared a series of questions for discussion under each section; proposed additions to or modifications of these should be addressed to M. le Baron Reille as above. The sections are as follows :-

I. Mathematical Section, including Mathematical Geography, Geodesy, and Topography. The following are some of the questions to be discussed in this section :Substitution of the centesimal division of the quadrant for the division called sexagesimal ; consequences relative to the division of time in astronomy.-Choice of a zero for a general level.-Measure of the differences of longitude; utilisation of telegraphic lines for the purpose of determining longitudes; advantages to geography by the electric telegraph.-Employment of chronometers. Measure of an arc of the meridian in the southern hemisphere, and particularly in the Argentine Republic.-The most simple instruments and the quickest methods for determining magnetic declination.

II. Hydrographical Section, including Hydrography and Maritime Geography.-Among the questions to be discussed in this section are the following :--Choice of a simple and uniform method for reckoning the points of the compass.-Researches concerning the depth to which the agitation of the surface of the sea penetrates.- Study of marine currents; question of the currents in straits. Determination of the temperature of the sea at different depths; instruments used; selection of the special points where these observations ought to be made.-Causes of the temperature of the Gulf Stream. - Programme of international instructions relative to observations which could usefully be made at once.

III. Physical Section, including Physical Geography, General Meteorology, General Geology, Botanical and
Zoological Geography, General Anthropology. Among the subjects proposed for discussion in this section are :New and well-established facts relative to the mobility of the crust of the earth during historical times.- Various theories as to the origin of mountains.--Lithology of the bed of the ocean, - Actual results of recent researches on. the influences exercised by astronomical phenomena, such as solar spots, meteoric showers, \&c.-To investigate new facts relative to the circulation of the atmosphere and the ocean, the movements of aërial and maritime currents, and their influence upon climates.-To discover the origin and general progress of great atmospheric whirlwinds or cyclones, as well as their periods ; to determine their duration, their force, and the extent of the countries exposed to their effects.-Means to be adopted in order to extend more widely the establishment and the discussion of simultaneous meteorological observations, recommended by the International Congress at Vienna.Geographical distribution of animal and vegetable species during tertiary times; consequences which fiow therefrom relative to the climatology of the globe during that period; geographical relation between the quaternary and the existing fauna and flora ; extinctions and migrations ; distribution of land and water during that period.-Species, genera, and families of plants which are characteristic of the great natural regions.-Also many questions relative to the geology, zoology, botany, anthropology, \&c., of the various great divisions of the globe-Europe, Asia, America, Oceania.

IV. Historical Section, including Historical Geography and the History of Geography, Ethnography, and Philology.- This section includes questions as to the condition of man both in prehistoric and historical times, comprehending the discussion of many particular points of history and ethnography.

V. Economical Section.-This section is concerned with subjects connected wirh Economical, Commercial, and Statistical Geography.

VI. The Didactic Section will discuss questions connected with Geographical Education and the diffusion of Geographical Knowledge.

VII. Section of Voyages, including explorations and voyages, scientific, commercial, and picturesque. In this section such points as the following are proposed for discussion :- How could a permanent bureau be constituted to indicate to travellers, by land and sea, the desidercati of geographical science?--Questions as to the undiscovered portion of Africa, as to the equipment of voyagers and travellers, instruments for various purposes, the bearing of explorers towards natives, narratives of travel, \&c., \&c.

There are proposed for discussion in the seven sec tions in all $x 23$ questions, of $\psi$ hich the above are a sample; and it will be seen, we think, that if the right men are induced to attend the Congress, and if the discussions are conducted in a truly scientific and candid spirit, great good must be the result to the many branches of science which are more or less connected with the subject of geography.

\section{THE LAST NEW COMET}

M R. J. R. HIND, F.R.S., writes as follows to the I Times from Mr. Bishop's Observatory, Twickenham, August I :- "From three consecutive nights' observations of the new comet of Marseilles, received from M. Stephan, I have calculated a first approximation to the orbit. It appears the comet will not reach its perihelion till about the 25 th inst., but is already slowly receding from the earth, being distant from us at the time of discovery about $55,000,000$ miles. Though it may continue visible in good telescopes for several weeks, it is not likely to become an object of any general interest, like the comet which has just left this hemisphere. The elements bear no resemblance to those of any comet previously computed." 